\title{
NEW TECHNOLOGIES FOR NEW ENVIRONMENTALLY ORIENTED EUROPEAN ECONOMICS: CADMIUM-FREE THIN FILM $\mathrm{CU}(\mathrm{IN}, \mathrm{GA}) \mathrm{SE}_{2} /\left(\mathrm{IN}_{2} \mathrm{~S}_{3}\right)$ HETEROPHOTOELEMENTS
}

\author{
Yuri Rud1 \\ Valeriy Gremenok2 \\ Vasiliy Rud',3 \\ ${ }^{\prime}$ Russian Academy of Sciences, Russia \\ ${ }^{2}$ National Academy of Sciences of Belarus, Belarus \\ ${ }^{3}$ Saint-Petersburg State Polytechnic University, Russia
}

\begin{abstract}
At present, the time has come to start the active search for commercial ecologically safe technologies for growing large-area CuInGaSe films and obtaining the thin film heterophotoelements on the basis of these films [1-4]. It is very benefitial task for new environmentally oriented European economics. We have long term experience with problem how to develop ecology safe heterophotoelements as high-efficiency photoconverters of solar radiation. First of all we have experiment with $\mathrm{CuInSe} 2 /$ green leafs heterojunctions [5-10], then we studied thin-film n- $\mathrm{ZnO}: \mathrm{Al} / \mathrm{p}-\mathrm{Cu}(\mathrm{In}, \mathrm{Ga}) \mathrm{Se}_{2}$ heterojunctions which was fabricated by magnetron sputtering of an $\mathrm{ZnO}$ target, leading to a deposition of $\mathrm{Cu}(\mathrm{In}, \mathrm{Ga}) \mathrm{Se}_{2}$ films on the surface [11]. This study is a continuation of the important line of research in modern photoenergy engineering and is concerned with development of the technology of cadmiumfree $\mathrm{Cu}(\mathrm{In}, \mathrm{Ga}) \mathrm{Se}_{2} / \mathrm{In}_{2} \mathrm{~S}_{3}$ thin film heterophotoelements.

The method of heat treatment of metallic $\mathrm{Cu}-\mathrm{In}-\mathrm{Ga}$ layers in the $\mathrm{N}_{2}$ inert atmosphere in the presence of selenium and sulfur vapors was used to grow homogeneous films of $\mathrm{Cu}(\mathrm{In}$, $\mathrm{Ga})(\mathrm{S}, \mathrm{Se})_{2}$ alloys onto which the $\mathrm{CdS}$ or $\operatorname{In}_{2} \mathrm{~S}_{3}$ films were deposited and, on the basis of these structures, the thin-film glass $/ \mathrm{Mo} / p-\mathrm{Cu}(\mathrm{In}, \mathrm{Ga})(\mathrm{S}, \mathrm{Se})_{2} / n-\left(\ln _{2} \mathrm{~S}_{3}, \mathrm{CdS}\right) / n-\mathrm{ZnO} / \mathrm{Ni}-\mathrm{Al}$ photoelements were fabricated. The mechanisms of charge transport and the processes of photosensitivity in the obtained structures subjected to irradiation with natural and linearly polarized light are discussed. The broadband photosensitivity of thin-film heterophotoelements and the induced photopleochroism were detected; these findings indicate that there is an interference-related blooming of the structures obtained.

It is concluded that it is possible to use ecologically safe cadmium-free thin-film heterostructures as high-efficiency photoconverters of solar radiation.
\end{abstract}

\section{KEYWORDS}

Heterophotoelements, Thin film, Photopleochroism, CIGS, Solar radiation, High efficiency, Photoconverters. 


\section{RESULTS AND DISCUSSION}

1.1. Homogeneous CuInGaSe films were obtained using heat treatment of the starting $\mathrm{Cu}-\mathrm{In}-$ Ga layers with the component composition necessary for the synthesis of the required solid solution. The $\mathrm{Cu}-\mathrm{In}-\mathrm{Ga}$ films were deposited using ion-plasma evaporation of the target of these metals in vacuum $\left(\sim 6 \times 10^{-4} \mathrm{~Pa}\right)$ onto glass substrates (either with a specially prepared surface or with a molybdenum sublayer) heated to $1008 \mathrm{C}$.

Heat treatment of the initial $\mathrm{Cu}-\mathrm{In}-\mathrm{Ga}$ films was carried out in the nitrogen inert atmosphere in the presence of selenium vapors in the temperature range of $250-520^{\circ} \mathrm{C}$. Physicochemical studies showed that these conditions of heat treatment ensured the synthesis of a quaternary solid solution with chalcopyrite structure $[12,13,14]$.

The duration of the process was chosen so as to satisfy the conditions for completion of the reaction of formation of homogeneous films of quaternary solid solution with the required composition. Studies of the films by the method of X-ray analysis using the $\mathrm{Cu} K_{\alpha}$ radiation and a $\mathrm{Ni}$ filter showed that the developed technology results in the formation of an equilibrium alloy with a chalcopyrite lattice whose parameters are consistent with Vegard's rule.

An analysis of the elemental composition of the grown films was performed using a PHI-660 scanning Auger microscope with spatial resolution of $\sim 0.1 \mu \mathrm{m}$ and sensitivity of $\sim 0.1$ at $\%$. It is worth noting that the obtained CuInGaSe films were highly homogeneous over the surface.

The combination of the performed studies of homogeneous $p$ - $\mathrm{Cu}(\mathrm{In}, \mathrm{Ga}) \mathrm{Se}_{2}$ films also indicated that it is possible to control the atomic composition and distribution of the component over the cross section [12,16]. The concentration of free holes at $T=300 \mathrm{~K}$ in the films under consideration was $\sim 2 \times 10 \mathrm{e}^{8} \mathrm{~cm}^{-3}$ and the hole mobility was about $70 \mathrm{~cm}^{2} \mathrm{~V}^{-1} \mathrm{~s}^{-1}$. In order to obtain a TFHP, we used the method of vacuum thermal evaporation to deposit $\operatorname{In}_{2} \mathrm{~S}_{3}$ films with the thickness of $\sim 40 \mathrm{~nm}$ onto the outer surface of the $p$-CuInGaSe films [8].

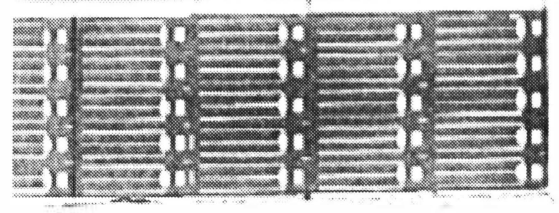

Figure 1. External appearance of a thin-film glass/Mo/p-Cu(In, Ga) Se $2 / n$ $\mathrm{In}_{2} \mathrm{~S}_{3} / \mathrm{n}-\mathrm{ZnO} / \mathrm{Ni}$-Al heterophotoelements on the substrate with dimensions $25 \times 75 \mathrm{~mm}$. The method of magnetron sputtering was used to deposit first a high-resistivity $\mathrm{ZnO}$ film $\left(d_{l} \approx 20-40 \mathrm{~nm}, \rho \approx 2.0 \times 10^{7} \Omega \mathrm{cm}\right)$ onto the surface of these films, followed by an aluminum-doped low-resistivity $n$ - $\mathrm{ZnO}$ film $\left(d_{l} \approx 0.5 \mathrm{~nm}, \rho \approx 3 \times 10^{-3}-3 \times 10^{-4} \Omega \mathrm{cm}, \mu=18\right.$ $\mathrm{cm}^{2} \mathrm{~V}^{-1} \mathrm{~s}^{-1}$, and $n=1.4 \times 10^{20} \mathrm{~cm}^{-3}$ at $\left.T=300 \mathrm{~K}\right)$. To conclude the process, we used the method of vacuum thermal evaporation through a mask to form $\mathrm{Ni}-\mathrm{Al}$ current contacts on the surface of the $n-\mathrm{ZnO}$ film. The thin-film glass $/ \mathrm{Mo} / p$ $\mathrm{Cu}(\mathrm{In}, \mathrm{Ga}) \mathrm{Se}_{2} / \mathrm{In} 2 \mathrm{~S} 3 / \mathrm{ZnO} / \mathrm{Ni}-\mathrm{Al}$ photoconverters were formed on the substrates with the dimensions $\sim 2 \times 25 \times 75 \mathrm{~mm}$; the method of mechanical scribing was then used to form a number of elements with the area of $\sim 5 \times 10 \mathrm{~mm}^{2}$, each of which was provided with a current contact; the Mo film with the thickness of $0.5-0.8 \mu \mathrm{m}$ deposited on the glass served as the common contact for all TFHPs. In Figure I, we show the external view of this photoelement. We also obtained the glass $/ p-\mathrm{Cu}(\mathrm{In}, \mathrm{Ga})(\mathrm{S}, \mathrm{Se})_{2} / \mathrm{CdS} / n-\mathrm{ZnO} / \mathrm{Ni}-\mathrm{Al}$ TFHPs in a similar way. The sulfur concentration in the $p-\mathrm{Cu}(\mathrm{In}, \mathrm{Ga})(\mathrm{S}, \mathrm{Se})_{2}(\mathrm{CuIn}-\mathrm{GaSSe})$ films was governed by the parameters of the sulfidizing process.

1.2. Studies of the static current-voltage $(I-V)$ characteristics showed that the obtained $\mathrm{Mo} / \mathrm{p}$ CuIn-GaSe/ $n-\operatorname{In} 2 \mathrm{~S} 3$ TFHPs exhibit pronounced rectification with the conducting direction 
always observed at the negative polarity of external bias applied to the $n$ - $\operatorname{In}_{2} S_{3}$ film. The rectification factor in the obtained TFHPs was $K \approx 3-25$ at the bias voltages $|U| \approx 1 \mathrm{~V}$. A typical $I-V$ characteristic of one of the CuInGaSe/In2S3 elements is shown in Fig. 2. The initial portion of the forward $I-V$ characteristic $(U<0.5 \mathrm{~V})$ for these structures is consistent with the well-known diode equation (Figure $2 b$, curve 1 ) with the diode factor $\beta \approx 1.93$. This value of $\beta$ indicates that the forward current is caused by recombination of charge carriers in the active region of these TFHPs. At the same time, for the Culn-GaSSe/CdS TFHP, we have $\beta \approx 4.25$, which is much larger than in the case of the $\mathrm{CuInGaSe} / \ln _{2} \mathrm{~S}_{3}$ barriers. This circumstance is typically related to variations in the charge transport due to a decrease in the structural quality of the heterointerface and indicates that the forward current is governed by the tunnel-recombination mechanism [15].

At the forward-bias voltages $U>0.5 \mathrm{~V}$ (Figure $2 a$ ), the $I-V$ characteristic of the structures based on $\operatorname{In}_{2} \mathrm{~S}_{3}$ and $\mathrm{CdS}$ starts to be linear,

$$
I=\frac{U-U_{0}}{R_{0}}
$$

where the cutoff voltage $U_{0}=0.3-0.4 \mathrm{~V}$, while the residual resistance $R_{0}$ for various structures varies in the range from 100 to $200 \Omega$ at $T=300 \mathrm{~K}$. The reverse portions of the $I-V$ characteristics of the compared types of TFHPs are typically described bythe power-law dependence $|I| \propto|U|^{\mathrm{m}}$, where the exponent $m$ is found to be close to unity at $|U| \leq 0.3 \mathrm{~V}$ (Figure 2c), which may indicate that there is tunneling of charge carriers or limitation of the current by the space charge in the saturation mode [1]. As the magnitude of the reverse-bias voltage is increased $(|U|>0.4 \mathrm{~V}$ ), the exponent attains a value of $m \approx 1.6$, which is consistent with the Childe-Langmuir law and is typically related to the currents limited by the space charge in the ballistic mode $[17,18]$.

Thus, the replacement of the CdS barrier layer by the $\operatorname{In}_{2} \mathrm{~S}_{3}$ layer in the obtained TFGPs does not bring about significant changes in their electrical properties but ensures the elimination of highly toxic cadmium from their composition.

1.3 The photovoltaic effect caused by separation of photogenerated charge-carrier pairs in the active region of the $\mathrm{CuInGaSe} / \mathrm{In} 2 \mathrm{~S} 3$ structures is clearly and reproducibly observed in the TFHPs based on the CuInGaSe films grown by selenization of the base $\mathrm{Cu}-\mathrm{In}-\mathrm{Ga}$ layers in the $\mathrm{N}_{2}$ atmosphere and subjected to illumination.

The dependence of the open-circuit photovoltage $U_{\mathrm{oc}}$ and the short-circuit current $J_{\mathrm{sc}}$, in accordance with [10], on the optical-flux power, is described by the logarithmic and linear laws, respectively. Also the values of $J_{\text {sc }}$ and the saturation photovoltage $U_{\infty}$ of typical TFPEs with the $\ln _{2} \mathrm{~S}_{3}$ and $\mathrm{CdS}$ barriers. It can be seen that, at the incident-radiation power $L \approx 100$ $\mathrm{mW} / \mathrm{cm}^{2}$, the maximum value $\mathrm{J}_{\mathrm{sc}}{ }^{\mathrm{m}} \approx 35 \mathrm{~mA} / \mathrm{cm}^{2}$ is attained in a TFHP with the $\mathrm{CuInGaSSe} / \mathrm{CdS}$ active region, which is close to the similar parameter in the conventionally used active region of the CuIn- GaSSe/CdS structure. A similar situation for the TFHPs to be compared is also observed in relation to $U_{0}$ close to the cutoff voltage $U_{0}$ in the same structures and can be identified with the energybarrier height that was found to be almost identical for the used barrier materials ( $\mathrm{CdS}$ and $\operatorname{In}_{2} \mathrm{~S}_{3}$ ).

It is worth noting that, in the TFHPs based on Culn-GaSe films and obtained by selenization, the saturation photovoltage $U_{\propto}$ was found to be almost two times lower than that for TFHPs based on thin films with similar composition and grown by coevaporation of the alloy's components [18]. At the same time, our analysis makes it possible to conclude that a higher 
quantum efficiency of photoconversion is attained if the barriers from $\ln 2 \mathrm{~S} 3$ films are used in TFHPs based on CuInGaSe layers.

1.4. In Figure 3, we show typical spectra of relative quantum efficiency of photoconversion $\eta(h \omega)$ for TFHPs obtained by deposition of the barrier films of In2S3 (curves 1, 1') and CdS (curves 2, 2') onto the surface of the films $\mathrm{Cu}(\mathrm{In}, \mathrm{Ga}) \mathrm{Se} 2$ and $\mathrm{Cu}(\mathrm{In}, \mathrm{Ga})(\mathrm{S}, \mathrm{Se}) 2$, respectively. It can be seen that a high photosensitivity is observed in a wide spectral range from 1 to $3.8 \mathrm{eV}$. A steep long-wavelength rise of photosensitivity is observed at $h \omega>0.95 \mathrm{eV}$ (Figure 3, curves I, 2). For both types of barriers, the dependences $\eta(h \omega)$ are linearized in the representation $(\eta \mathrm{h} \omega)^{2}=f(\mathrm{~h} \omega)$ (Figure 3, curves 1', 2'). The extrapolation $(\eta \mathrm{h} \omega)^{2} \rightarrow 0$ on the basis of the theory of interband absorption in semiconductors [15] made it possible to determine the band gap for direct interband transitions; the value of $E^{d}{ }_{\mathrm{G}}$ is in satisfactory agreement with the corresponding estimates based on the data on optical transmission of the same films. It is noteworthy that the spectral contour $\eta(\mathrm{h} \omega)$ and the value of determined $E_{\mathrm{G}}^{d}$ from the measurements of photosensitivity of the barriers under study were found to be quite reproducible over the entire area of the films. This finding is also consistent with the electronmicroscopy data on the high local homogeneity of the films grown in the processes of selenization and sulfurization of metallic $\mathrm{Cu}-\mathrm{In}-\mathrm{Ga}$ layers.
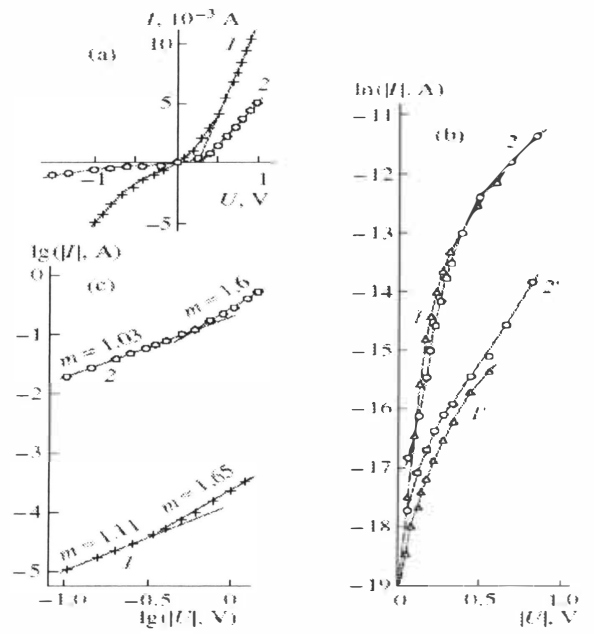

Figure2 .Static current-voltage characteristics $(T=300 \mathrm{~K})$ of the heterophotoelements glass/Mo/p-Cu(In, Ga)Se $2 / n-I n_{2} S_{3} / n-Z n O / N i-A l(s a m p l e ~ M X 20 I-2$, curves $I$ and I')and glass/Mo/p-Cu(In,Ga)(S,Se) $/ n$-CdS//n-ZnO/Ni-Al(sample IMXI78S, curves 2 and 2') in the representations (a) $I=f(U),(b) \ln / I /=f(U)$, and (c). $\log / I /=f(\log U)$ 
increased $\left(\mathrm{h} \omega>E_{\mathrm{G}}^{d}\right.$ ), the photosensitivity continues to increase in the spectra $\eta(\mathrm{h} \omega)$ for photoelements based on different barrier materials (CdS and $\operatorname{In}_{2} S_{3}$ ); the photosensitivity $\eta\rceil$ starts to gradually decrease only at $h \omega>1.6 \mathrm{eV}$. As a result, the total width of the $\eta(h \omega)$ spectra at their half-height for the best structures based on the $\operatorname{In}_{2} S_{3}$ and CdS films was found to be as large as $\delta_{1 / 2} \approx 1.95 \mathrm{eV}$ for both types of structures. This finding indicates that the quality of the interface is fairly high and is not worsened as a result of replacement CdS $\rightarrow \ln _{2} S_{3}$, which is also corroborated by the close values of photocurrent $J_{\text {sc }}$ in the TFHPs

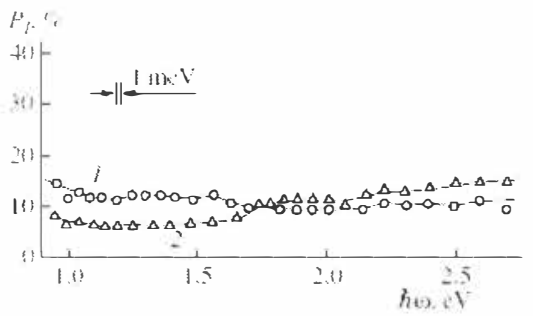

Figure 5. Spectra $P_{l}(h \omega)$ of heterophotoelements glass/Mo/p-

$\mathrm{Cu}(\mathrm{In}, \mathrm{Ga}) \mathrm{Se}_{2} / \mathrm{n}^{-}-\mathrm{In}_{2} \mathrm{~S}_{3} / \mathrm{n}-\mathrm{ZnO} / \mathrm{Ni}-\mathrm{Al}$ (sample IMX201-2,

curve l) and glass/Mo/p-Cu(In, Ga)(S, $\mathrm{Se})_{2} / \mathrm{CdS} / \mathrm{n}-\mathrm{ZnO} / \mathrm{Ni}-\mathrm{Al}$

IMXI78S, curve 2) at $T=300 \mathrm{~K}$. under comparison. The highest voltage sensitivity $\mathrm{S}_{\mathrm{U}}{ }^{\mathrm{m}} \approx 400 \mathrm{~V} / \mathrm{W}$ is observed for a TFHP based on the CuInGaSe/ $\mathrm{In}_{2} \mathrm{~S}_{3}$ barrier; the highest quantum efficiency is also characteristic of this TFHP.

2.5. Using irradiation of TFHPs with linearly polarized light (LPL), [18,19] established that there is no natural photopleochroism in these photoelements. This feature is related to the fact that all layers of these TFHPs are polycrystalline. Under conditions of oblique incidence of LPL on the receiving $\mathrm{ZnO}$ plane, as soon as the angle of incidence Obecomes nonzero, the TFHP starts to exhibit induced photopleochroism $P_{I}>0$ [19]. In Figure 4, we show the typical dependence of the induced-photopleochroism coefficient on the angle of incidence of LPL. It follows from Figure 4 that this dependence is consistent with the theory and is described

by the square law $[14,15]$

$$
P, \infty \Theta^{2}
$$

for both types of TFHPs (curves 1, 2). However, the coefficient of induced photopleochroism was found to be much smaller than the value estimated from the theory $P_{I} \approx 30 \%$, with rgw refractive index of $\mathrm{ZnO}$ taken into account $[19,20]$.

Typical $P_{/}(\mathrm{h} \omega)$ spectra at a fixed angle of the LPL incidence $\Theta=70^{\circ}$. for TFHPs with the $\operatorname{In}_{2} \mathrm{~S}_{3}$ and CdS barrier forms are shown in Figure 5. It can be seen that the coefficient of induced photopleochroism depends only slightly on the photon energy and is extremely small in the entire range of photosensitivity. The value of this coefficient is about two times smaller than what is expected from the theory [19]. We can state that the established trends of induced photopleochroism in the obtained TFHPs are indicative of the effect of interference- related bleaching of these photoelements in the entire spectral range of photoconversion as a result of deposition of thin $\mathrm{ZnO}$ films onto the outer plane of the CdS and $\operatorname{In}_{2} \mathrm{~S}_{3}$ barrier layers [14, 15]. Evidently, the optimization of magnetron-assisted deposition of $\mathrm{ZnO}$ films would make it possible to increase the quantum efficiency of photoconversion in a TFHP, while the use of polarization photoelectric spectroscopy ensures the rapid monitoring of the processes of formation of antireflection single-layer coatings from thin $\mathrm{ZnO}$ films. 


\section{CONCLUSIONS}

We used heat treatment of the base $\mathrm{Cu}-\mathrm{In}-\mathrm{Ga}$ layers in the $\mathrm{N}_{2}$ inert atmosphere in the presence of selenium and sulfur vapors to synthesize homogeneous films of $\mathrm{Cu}(\mathrm{In}, \mathrm{Ga})(\mathrm{S}$, $\mathrm{Se})_{2}$ solid solutions; $\mathrm{CdS}$ or $\operatorname{In}_{2} \mathrm{~S}_{3}$ films were then deposited onto the solid-solution films and finally the glass $/ \mathrm{Mo} / p-\mathrm{Cu}(\mathrm{In}, \mathrm{Ga})(\mathrm{S}, \mathrm{Se})_{2} / n-\left(\operatorname{In}_{2} \mathrm{~S}_{3}, \mathrm{CdS}\right) / n-\mathrm{ZnO} / \mathrm{Ni}-\mathrm{Al}$ were formed. An analysis of the charge-transport mechanism showed that replacement of the barrier layer CdS by $\mathrm{In}_{2} \mathrm{~S}_{3}$ in the obtained TFHPs does not result in significant changes in the electrical properties of these photoelements. Observed broadband photosensitivity of thin-film heterophotoelements and induced photopleochroism are indicative of interference- related bleaching of the obtained structures. It is established that higher quantum efficiency of photoconversion in the heterophotoelements based on $\mathrm{Cu}(\mathrm{In}, \mathrm{Ga})(\mathrm{S}, \mathrm{Se})_{2}$ is attained if thin $\mathrm{In}_{2} \mathrm{~S}_{3}$ films are used as barriers.

Thus, as a result of the carried-out physicotechnological study, we established that $\ln _{2} \mathrm{~S}_{3}$ films can be introduced into TFHP structure as barriers. This technology can be used in the fabrication of high-efficiency and ecologically safe cadmium-free next-generation TFHPs, while the use of polarization photoelectric spectroscopy can ensure the monitoring of the widerange blooming of these photoelements.

\section{ACKNOWLEDGEMENTS}

This study was supported by the Interdisciplinary Scientific and Technological Center (project no. V-1029) and by the program of the Physical Sciences Department of the Russian Academy of Sciences "New Principles of Energy Conversion in Semiconductor Structures."

\section{REFERENCES}

[1]. V. Nadenau, D. Braunder, D. Hariskos, at al., Prog. Photovoltaics 3, 363(1995).

[2]. U. Rau and H. W. Schock, Renewable Sustainable Energy Rev. 1,277(2001).

[3] K. Zweibel, "The Terawatt Challenge for Thin-Film PV," NREL Technical Report, NREL/TP-520-38350 (08/2005).

[4] B. von Roedern, K. Zweibel, and H.S. Ullal, "The Role of Polycrystalline Thin-Film PV Technologies for Achieving Mid-Term Market-Competitive PV Modules," Proc. 31st IEEE PV Spec. Confe(Lake Buena Vista, FL, 01/2005), 183.

[5] V.Yu. Rud', Yu.V. Rud', T. Walter, H.W.Schock, Inst. Phys. Conf. Ser. 152. IOP Publishing Ltd. 971 (1998)

[6] V.Yu.Rud', Yu.V.Rud', Semiconductors 31 ( 11 ), 1151 (1997)

[7] V.Yu.Rud', Yu.V. Rud', V.Ch. Shpunt, Semiconductors 31 ( 2 ), 97 (1997)

[8] V.Yu.Rud', Yu.V. Rud', V.Ch. Shpunt, S. Iida, Inst. Phys. Conf. Ser. 152. IOP Publishing Ltd. 997 (1998)

[9] I.V.Bodnar, A.A.Vaipolin, V.Yu.Rud', Yu.V. Rud', Semiconductors 28 ( 8 ), 746 (1994)

[10] F. P. Kesamanly, V. Yu. Rud', and Yu. V. Rud', Semiconductors 33, 483 (1999).

[11] V.Yu. Rud' at all, IV-th International Youth Scientific Environmental Forum "ECOBALTICA'2006". Proceedings Book. June 2006. St.-Petersburg. 40-44.2006.

[12 ] V.F. Gremenok, E.P. Zaretskaya, V.B. Zalesski, K. Bente, W. Schmitz, R.W. Martin, H.J. Moller. Sol. Energy Mater. And Solar Cells, 89, 129 (2005).

$[13$ ]. I. V. Bodnar', V. A. Polubok, V. F. Gremenok, V.Yu.Rud', Yu.V. Rud', Semiconductors 41, 47 (2007).

[14 ]. A. M. Polikanin, O. V. Goncharova, S. A. Sergienya, et al., Zh. Prikl. Spektrosk. 71, 683 (2004). 
[15 ]. S. M. Sze, Physics of Semiconductor Devices, 2nd ed. (Wiley, New York, 1981; Mir, Moscow, 1984).

[16e]. M.eA. Lampert and P. Mark, Current Injection in Solids (Academic, New York, 1970; Mir, Moscow, 1973).

[17 ]. E. Hernandes, Cryst. Res. Technol. 33, 285 (1988).

[18]. V. Yu. Rud', Yu. V. Rud', and H.-W. Schock, Solid State Phenom. 67-68, 421 (1999).

[19]. V. Yu. Rud', Doctoral Dissertation (Ul'yanovsk State Univ., Ul'yanovsk, 2005). 